\title{
Higher Education Under Surveillance
}

\author{
Allyson Skene, Jessica Raffoul, Laura Chittle \\ University of Windsor
}

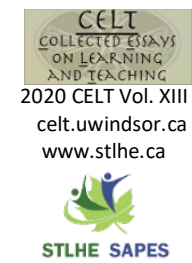

A ll over the world, institutions of higher education are facing increasing calls from governments, student groups, community members, and concerned citizens for accountability and greater transparency in decision-making. It is quite difficult to, in good faith, argue against these demands for accountability and transparency: in Canada, education is partially supported by the public purse, and students bear great financial burdens to attend college or university. A clear understanding of how resources are allocated, programs are structured, research is undertaken, and teaching is articulated might help foster a sense of trust and reciprocity between postsecondary institutions and their communities. Accountability can also promote the effective use of resources and, under ideal circumstances, help ensure that higher education is both accessible to marginalized populations and serving the needs of diverse students.

Over the last 30 years, post-secondary institutions have met demands to provide evidence of their quality and effectiveness with hurried timelines, funding consequences, and questionable indicators. For example, certain government agencies are requiring more and more evidence from colleges and universities that they are efficient, effective, and relevant by calling for numbers, key performance indicators, benchmarks, and quality assurance protocols - that is, evidence based on productivity, 'economic efficiency', and 'value for money' (Power, 1994; Shore, 2008; Shore \& Wright, 2004, 2015). In this context, quality is determined by what is most visible to external scrutiny, and accountability has become conflated with accountancy, giving rise to what researchers have called "audit culture" (Power, 1994; Shore \& Wright, 2004). The results are often deleterious - reducing the complex social practices of

higher education to oversimplified numbers while eroding trust, dismantling collegiality, and limiting creativity (Craig et al., 2014; Shore, 2008; Tsoukas, 1997). Paradoxically, this audit culture frequently subverts the very aim of accountability by forcing us to adopt a crude managerial perspective rather than focusing on high ideals (Gibbs, 2013; Power, 1994).

In this paper, we will explore how audit culture has emerged in higher education by critiquing the many ways in which it directs our energies towards processes of compliance and by discussing how we might report on accountability without sacrificing quality. In the end, we will propose strategies for navigating audit and accountability culture while meeting external requirements and maintaining the values and principles of higher education.

\section{The Audit Culture: An Evolution}

Oxford's Dictionary defines the term 'audit' as a systematic, official inspection of an individual's or organization's accounts. Originating in fifteenthcentury Britain, audits first appeared in the financial district as accountants requested that landed estates be read aloud so that they could be publicly scrutinized for accuracy and cited for fraud (Matthews, 2006).

Towards the end of the twentieth century, the term migrated into the public sector and began to infiltrate numerous corners of professional life as a means to scrutinize performance and efficiency (Shore \& Wright, 2000; Taubman, 2010). While market forces were seen as providing adequate regulation for the private sector, the public sector was criticized for lacking transparency and fiscal 
responsibility. As such, government agencies invoked extensive auditing as a reasonable, technical solution to ensure that they were not wasting public resources or misrepresenting their activities. It is critical to note that because the process involved independent observers, it was seen as a rational, objective, and neutral solution to the problem of providing accountability and ensuring integrity (Power, 1994; Shore \& Wright, 2000). Consumer and public interests were believed to be protected through the values of economic efficiency underlying the aims of the audit. Because it seemed to provide an effective solution to a number of problems, the audit has since spread exponentially to include the measurement and organization of virtually every aspect of life (Power, 2004; Shore, 2008; Shore \& Wright, 2000). This consequent shift in technique and governance, which has evolved into the "measurement and ordering of culture itself," is at the heart of what has been termed 'audit culture' (Shore \& Wright, 2004, p. 103).

\section{The Audit Culture in Higher Education: A Critique}

Institutions of higher education have not been immune to the emergence of this culture of audit and inspection. In fact, post-secondary institutions around the world have seen an increase in government oversight and regulation over the last two decades (Craig et al., 2014), and have been called on to provide evidence of accountability, which, at times, has been tied to funding.

It is important to note that, on its own, the term "audit" carries negative connotations. Audits arise in situations and relationships where there is a need for accountability but the 'subject' cannot be trusted enough to deliver accurate information or uphold their end of a contract (Power, 1994). Auditing bodies enlist an external monitor intended to be an objective observer and thereby reduce the risk of misinformation, deception, and dishonesty. The audit is, at its core, rooted in a lack of trust and a refusal to recognize integrity in self-governance.

Worse yet, the audit, when applied to social practices, erodes trust even further (Craig et al., 2014).
The dual nature of the audit necessitates a disproportionate relationship between the observer and the observed, the scrutinizer and the scrutinized (Foucault, 1977; Power, 1994), that can interfere with collegial relations in the university community. For example, administrators and centres for teaching and learning (CTLs) have often taken on the role of the assessor of faculties, disciplines, and programs, consequently appearing as though they are singlehandedly determining the good from the bad, the effective from the ineffective (Craig et al., 2014). This can lead colleagues to view these groups with suspicion, making it nearly impossible to maintain collegiality (Power, 1994; Shore \& Wright, 2000, 2015). In addition, the use of performance metrics to label students or place them into categories and monitor their performance, engagement, social interactions, and so on, is arguably an erosion of their privacy and can lead to the further marginalization of already marginalized students (Slade \& Prinsloo, 2013).

The audit, with its foothold in the financial realm and its measurement of quality primarily via numbers, carries many far-reaching assumptionsthat it measures accountability, that it provides transparency, and that it ensures integrity. While the intent behind audit usage in the post-secondary sector may be to ensure quality, it is unclear whether they achieve this goal. In fact, accountability does not actually lead to an improvement in quality in many cases (Power, 1994). Does tracking students actually help them? Do graduation rates reflect the quality of the education offered? Do post-secondary institutions share this information purely for marketing purposes? An emphasis on transferable skills in "isolation from disciplinary "content," (MacRury, 2007, p. 123-124) along with quantitative metrics used to articulate teaching and research productivity, student employability, and satisfaction do not, on their own, ensure accountability and integrity.

When funding is inextricably tied to an institution's ability to meet metrics, a few things are bound to happen: first, meeting demands for accountability translates into a large amount of time 
spent complying with accountability requirements. This is particularly damaging as professors, staff members, and administrators across the sector are already overstretched with larger class sizes, an increasing workload, and numerous inflexible deadlines. Rather than finding ways to authentically assess and communicate effectiveness and quality, many academics find themselves compiling institutional analytics, filling annual reports with enrolment data, or spinning the metrics so that they tell the "right" story (Shore \& Wright, 2015). The constant need to produce observable traces with which to articulate impact (e.g., Foucault, 1977, 1980) shifts our energies more and more towards processes of compliance: counting attendances, student evaluations of teaching scores, curriculum maps, learning outcomes, and so on.

Second, institutions are increasingly competing with one another to meet metrics in a sort of survivor's race for scarce resources (Shore and Wright, 2015). This context can lead to paranoia within and between disciplines who do not appear to meet standards set by external bodies, a rise in contract workers hired solely to meet metrics, and, what some might deem, a cheapened 'degree' through grade inflation and lower admission and quality standards (Taubman, 2010). These and other practices that create the illusion of higher recruitment, achievement, and graduation rates are a product of post-secondary institutions learning "to game the system by applying effort to manage the scores they receive... [a] practice facilitated by the loss of richness of context" in favour of "auditable performance measures” (Craig et al., 2014, p. 10).

Third, the values underlying the audit—with its focus on inspection and scrutiny, and a subtext riddled with assumptions around efficiency at any cost-may infect the values that have sustained higher education's long-standing effects on and impacts in our communities. Disciplinary and pedagogical values around quality of research and student skill development are replaced with generic metrics that focus on counting publications or ranking journals and shuffling large numbers of students through a system and into lucrative jobs as quickly as possible. As a consequence, “"efficiency” and a 'consumer orientation' have become the core values" of a post-secondary degree (Shore \& Wright, 2004, p. 104). Consider, for example, the emphasis on being 'workplace ready' - a focus that is not at its core wrong or misdirected, but in its expression can impact what Faculties are able to teach, and influence what students choose to study. Many students opt to move into professional degrees that make them employable rather than choosing to enroll in a discipline that they care about.

For all of these reasons - the erosion of trust and collegiality, funding implications leading to competition between institutions, and assumptions underlying metrics - the audit undermines institutional values and the ability of departments and faculties to enhance teaching and learning. These factors may explain why research has shown that quality assurance practices are often not connected to improvement or, worse, inversely related to it (Liu, 2020).

\section{Navigating Culture and Redefining the Audit: An Ethical Response}

The impact of audit culture on higher education is not purely neutral or passive but is embedded in its very fabric, actively shaping the institution, its people, and its operations (Foucault, 1977, 1980; Power, 1994). It is critical, then, that practitioners who work to advance teaching and support development learn to navigate this terrain in a way that focuses on the positive relationships and ideas that can result from reporting and accountability practices.

When focused on improvement and enhancement, accountability can open more channels for dialogue, feedback, and revision. For example, in the context of curriculum review and analysis, mandated by many provincial governments, the development of maps and investigation into graduate outcomes can provide a great deal of insight into how programs function and whether we are effectively supporting the development and articulation of 
transformational and transferable learning and skills. In fact, the literature on curriculum review indicates that one of the net benefits of the process is encouraging dialogue and collegiality (Liu, 2020; Uchiyama \& Radin, 2009; Wolf, 2007). Viewing teaching and teaching development as a public enterprise rather than a private one helps to build connections, establish communities, and foster networks of champions across campuses and disciplines.

Similarly, transparency in teaching and curriculum design can benefit students and support their development. Clear learning outcomes and assessment prompts provide students a sense of purpose, direction, and agency as learners; furthermore, mapped curricula can help faculty identify and mitigate potential gaps and bottlenecks in their programs. Work on these initiatives could result in centralized resources (e.g. learning outcome guides, curriculum mapping tools, etc.) freely available to faculty.

The question is not whether accountability can be useful, but how to harness accountability in ways that promote our goals rather than detract from them. Craig et al. (2014) argue that academics should "think about accountability in ways that embrace more responsible features of a modified collegial control," supplementing "brute financial accountability with compassion, multiplicity, social welfare, social responsibility, equity, and trust" (p. 19).

As a first step, then, we must avoid the 'fear of being seen.' Transparency and openness do not necessarily impinge on academic freedom, but instead support a movement towards collegial contribution and control. It is important to note that, ironically, it is through providing evidence of merit and meeting metrics that we actually acquire academic freedom through promotion and tenure processes. By refocusing metrics to align with our academic values, we can avoid the "psychotic" spiral (Craig et al., 2014) of continually developing and enforcing metrics that undermine those values.

Second, as resistance is one way to challenge audit culture (Shore \& Wright, 2015), institutions could consider banding together to lobby governments for metrics that are well grounded in literature on teaching and learning improvement rather than those that might place more value on economic efficiency. For example, while student to faculty ratios are not always indicative of learning, they are at least rooted in empirical evidence of effective undergraduate education and speak to the importance of encouraging contact between students and faculty (e.g., Chickering \& Gamson, 1987). Similarly, focusing on measures that identify studentinstructor collaboration, class sizes, amount of formative feedback, or available library resources would be more effective than focusing on outputs. The idea is not to dismiss metrics altogether, as these can often be both illuminating and persuasive, particularly in conversations around budgets and personnel, but to challenge the assumptions and philosophical values that underlie them and remember that quantifiable data, when used to assess quality and understand impact, results in an incomplete picture.

Audit metrics tend to be instrumental and focused on normative performance measures that foster competitiveness both within and between universities; a better approach might be the use of metrics that deliberately focus on process, learning, and ensuring equity among marginalized groups. Initiatives like the National Survey on Student Engagement (NSSE) provide a starting point by drawing on student perspectives; however, they restrict feedback to students in their first and last years of study, which is informative but neglects students' experiences in the midst of their studies. Moreover, the NSSE's approach in capturing and reporting on performance indicators does not necessarily consider the quality of these experiences or the context within which they occur. For example, the NSSE asks students whether they have engaged in research with a faculty member (or plan to), but it does not assess whether students have acquired the skills and benefits of engaging in research through these experiences (e.g., improved skills in problemsolving, critical thinking, synthesizing information, 
communication, and independent learning; Miller et al., 2008).

Similarly, institutions can identify measures that highlight process and support rather than focus on the number of dollars students earn after graduation, which might result in students choosing disciplines based on employability over interest or skill. For example, institutions can launch small-scale grants that support experiential initiatives and meaningful internships in disciplines on the outskirts of the employability movement, such as many of the arts and humanities. Institutions can also support and encourage co-curricular initiatives and facilitate richer connections with communities and professional designations. These approaches are well-grounded in evidence of effective education that supports significant learning, yet they are almost never included in formal 'quality assurance' metrics (Gibbs, 2012).

Authentically collecting data to report on accountability is more time consuming than the collection of numbers. And, as long as organizations stand to benefit from meeting the demands of audit culture, there will be little incentive for change. The transformation of financial, efficiency, and audit metrics into accountability standards that reflect academic values will occur at specific points of resistance and through collective action from the ground (e.g., Shore \& Wright, 2015). While budgets are always a practical challenge, faculties could advocate for full-time positions within their departments that are committed to the improvement of quality teaching and programs.

In ideal situations, we can contribute to a culture of reflection, critique, and feedback, which are all values of higher education, by collaboratively and authentically reporting on practices and their impacts. In this context, students have a voice in, and eyes on, their learning; teaching is evaluated by more than a single, uncontextualized score, and disciplines are assessed by experiences over 'bums in seats.' Goff (2017), for example, outlines how differing conceptions of quality on the part of university administrators can inform the approaches taken by the institution towards quality assurance. A focus on enhancing quality allows more space for interim and process-informed metrics and data that contribute to ongoing improvement.

By engaging in public dialogue (e.g., Bamber \& Stefani, 2016; Craig et al., 2014; Power, 1994) and focusing on program enhancement and students' academic experiences, we can make strides towards a culture that respects accountability.

\section{References}

Bamber, V. \& Stefani, L. (2016). Taking up the challenge of evidencing value in educational development: from theory to practice, International Journal for Academic Development, 21(3), 242-254. doi: 10.1080/1360144X.2015.1100112

Chickering, A.W. \& Gamson, Z. F. (1987). Seven principles for good practice in undergraduate education. AAHE bulletin, 3, 7.

Craig, R., Amernic, J., \& Tourish, D. (2014). Perverse audit culture and accountability of the modern public university. Financial Accountability \& Management, 30(1), 1-24. doi: $\underline{10.1111 / \text { faam.12025 }}$

Foucault, M. (1977). Discipline and punish: The birth of the prison. Trans. Alan Sheridan, New York: Vintage.

Foucault, M. (1980). Power/knowledge: Selected interviews and other writings, 1972-1977. Vintage.

Gibbs, G. (2012). Implications of 'Dimensions of quality'in a market environment. York: Higher Education Academy.

Gibbs, G. (2013). Reflections on the changing nature of educational development. International Journal for Academic Development, 18(1), 4-14. doi: $\quad 10.1007 / \mathrm{s} 10734-016-0042-$ $\underline{810.1080 / 1360144 X .2013 .751691}$

Goff, L. (2017). University administrators' conceptions of quality and approaches to quality assurance. Higher Education, 74(1), 179-195. doi: $10.1007 / \mathrm{s} 10734-016-0042-8$ 
Liu, Q. (2020). The Impact of Quality Assurance Policies on Curriculum Development in Ontario Postsecondary Education. Canadian Journal of Higher Education, 50(1), 53-67.

MacRury, I. (2007). Institutional creativity and pathologies of potential space: The modern university. Psychodynamic Practice, 13(2), 119140. doi: $10.1080 / 14753630701273058$

Matthews, D. (2006). A history of auditing: The changing audit process in Britain from the nineteenth century to the present day. London: Routledge.

Power, M. (1994). The audit explosion. London: White Dove Press.

Shore, C. (2008). Audit culture and illiberal governance: Universities and the politics of accountability. Anthropological Theory, 8(3), $278-298$.

$10.1177 \% 2 \mathrm{~F} 1463499608093815$

Shore, C. \& Wright, S. (2000). Coercive accountability: The rise of audit culture in higher education. In Strathern M. (Ed.), Audit cultures: Anthropological studies in accountability, etbics and the academy (pp. 57-89), London: Routledge.

Shore, C., \& Wright, S. (2004). Whose accountability? Governmentality and the auditing of universities. parallax, 10(2), 100-116. doi: $\underline{10.1080 / 1353464042000208558}$

Shore, C., \& Wright, S. (2015). Audit culture revisited: rankings, ratings, and the reassembling of society. Current Anthropology, 56(3), 421-431

Slade, S. \& Prinsloo, P. (2013). Learning analytics: Ethical issues and dilemmas. American Behavioral Scientist, 57(10), 1510-1529. doi: $\underline{10.1177 / 0002764213479366 .}$

Taubman, P. M. (2010). Teaching by numbers: Deconstructing the discourse of standards and accountability in education. London: Routledge.

Tsoukas, H. (1997). The tyranny of light: The temptations and the paradoxes of the information society. Futures, 29(9), 827-843. doi: 10.1016/S0016-3287(97)00035-9
Uchiyama, K.P. \& Radin, J. L. (2009). Curriculum mapping in higher education: A vehicle for collaboration. Innovative Higher Education, 33(4), 271-280. doi: 10.1007/s10755-008$\underline{9078-8}$

Wolf, P. (2007). A model for facilitating curriculum development in higher education: A facultydriven, data-informed, and educational developer-supported approach. New Directions for Teaching and Learning, 117, 15-20. doi: $10.1002 / \mathrm{tl} .294$

\section{Biographies}

Allyson Skene is a Learning Specialist at the University of Windsor. She works with faculty, staff, and graduate students supporting teaching and learning, with a focus on curriculum development and learning analytics.

Jessica Raffoul is a Learning Specialist at the University of Windsor where she designs and contributes to research, programs, and curricula that support teaching and learning.

Laura Chittle is a Postdoctoral Fellow in the Faculty of Science at the University of Windsor where she also coordinates the GATA Network within the Centre for Teaching and Learning. 